\title{
PENGARUH KEPERCAYAAN PADA PIMPINAN, MUTASI DAN BUDAYA ORGANISASI TERHADAP MOTIVASI KERJA DAN KINERJA PEGAWAI DI BADAN PENDAPATAN DAERAH KABUPATEN JEMBER
}

\author{
Arief Yudho Prasetyo \\ Fakultas Ekonomi Dan Bisnis Universitas Jember \\ ariefyudho1984@gmail.com \\ Andi Sularso \\ Fakultas Ekonomi Dan Bisnis Universitas Jember \\ Handriyono \\ Fakultas Ekonomi Dan Bisnis Universitas Jember
}

\begin{abstract}
The purpose of this study is to examine the influence of trust towards the leader, mutation, and organizational culture on work motivation and employee performance at Regional Revenue Board of Jember Regency. This is an explanatory research with the sample consists of 150 employees of Regional Revenue Board of Jember Regency. Data were analyzed using Structural Equation Modelling (SEM). Results show that trust towards the leader, mutation, and organizational culture have significant effects on work motivation; mutation and work motivation have significant effects on employee performance. However, trust towards the leader and organizational culture have no significant effects on the employee performance at Regional Revenue Board of Jember Regency.
\end{abstract}

Keywords: Trust towards the Leaders, Mutation, Organizational Culture, Work Motivation, and Performance

\begin{abstract}
Abstrak: Tujuan penelitian ini adalah untuk menguji pengaruh kepercayaan terhadap pimpinan, mutasi, dan budaya organisasi terhadap motivasi kerja dan kinerja pegawai pada Badan Pendapatan Daerah Kabupaten Jember. Penelitian ini merupakan explanatory research. Sampel penelitian terdiri dari 150 orang pegawai Badan Pendapatan Daerah Kabupaten Jember. Metode analisis data menggunakan SEM. Hasil penelitian menunjukkan bahwa kepercayaan terhadap pimpinan, mutasi, dan budaya organisasi berpengaruh signifikan terhadap motivasi kerja; mutasi dan motivasi kerja berpengaruh signifikan terhadap kinerja. Namun, kepercayaan terhadap pimpinan dan budaya organisasi tidak berpengaruh signifikan terhadap kinerja pegawai Badan Pendapatan Daerah Kabupaten Jember.
\end{abstract}

Kata Kunci: Kepercayaan terhadap Pimpinan, Mutasi, Budaya Organisasi, Motivasi Kerja, dan Kinerja.

\section{Pendahuluan}

Badan Pendapatan Daerah Kabupaten Jember sebagai instansi pemerintah yang melaksanakan kekuasaan negara dengan kerjasama dan koordinasi di bidang pelaksanaan pendapatan asli daerah dengan seluruh instansi pemerintah di Kabupaten Jember. Komitmen pada organisasi didefinisikan sebagai 
suatu keadaan dimana seorang pegawai memihak pada suatu organisasi tertentu dan tujuan-tujuannya, serta berniat memelihara keanggotaan diorganisasi itu. Jadi keterlibatan kerja yang tinggi berarti pemihakan seseorang pada pekerjannya yang khusus.

Adanya kurang ketidaktercapaian kinerja disebabkan oleh berbagai faktor yang terjadi Badan Pendapatan Daerah Kabupaten Jember. Pelaksanaan mutasi pegawai dari satu seksi satu ke seksi lain belum sepenuhnya berjalan sehingga terjadi ketidakseimbangan pegawai, timbulnya rasa bosan di suatu tempat sehingga dapat mempengaruhi kinerja pegawai dan berpengaruh pada kinerja organisasi. Adanya mutasi diharapkan dapat meningkatkan kinerja pegawai dan sebagai alat pendorong agar motivasi kerja pegawai meningkat dan untuk menghilangkan rasa bosan/jenuh terhadap pekerjaanya agar tercipta penyegaran terhadap pegawai yang juga akan terjadi penyegaran organisasi

Berdasarkan fenomena tersebut maka penelitian ini dilakukan untuk dengan melihat pentingnya pengaruh kepercayaan terhadap pimpinan, mutasi dan budaya organisasi terhadap motivasi kerja untuk meningkatkan kinerja pegawai pada Badan Pendapatan Daerah Kabupaten Jember.

Tujuan yang hendak dicapai pada penelitian ini adalah: (a) Menguji pengaruh mutasi terhadap motivasi kerja pegawai pada Badan Pendapatan Daerah Kabupaten Jember; (b) Menguji terdapat pengaruh budaya organisasi terhadap motivasi kerja pegawai pada Badan Pendapatan Daerah Kabupaten Jember; (c) Menguji terdapat pengaruh kepercayaan terhadap pimpinan terhadap motivasi kerja pegawai pada Badan Pendapatan Daerah Kabupaten Jember; (d) Menguji terdapat pengaruh motivasi kerja terhadap kinerja pegawai pada Badan Pendapatan Daerah Kabupaten Jember; (e) Menguji terdapat pengaruh mutasi terhadap kinerja pegawai pada Badan Pendapatan Daerah Kabupaten Jember; (f) Menguji terdapat pengaruh budaya organisasi terhadap kinerja pegawai pada Badan Pendapatan Daerah Kabupaten Jember; (g) Menguji terdapat pengaruh kepercayaan terhadap pimpinan terhadap kinerja pegawai pada Badan Pendapatan Daerah Kabupaten Jember.

\section{Metodologi}

Penelitian ini termasuk dalam penelitian penjelasan (explanatory research) karena penelitian ini bermaksud menjelaskan hubungan kausal (sebab akibat) antara variabel melalui pengujian hipotesis yang telah dirumuskan (Kuncoro, 2004:67). Data primer dalam penelitian ini adalah hasil kuisioner dari variabel penelitian yang diisi 
oleh responden. Data sekunder penelitian ini data pegawai Badan Pendapatan Daerah Kabupaten Jember yang berjumlah 150 orang dengan variabel-variabel yang akan dianalisis sebagai berikut:

a. Variabel Independent (Exogenous) mencakup 3 (tiga), yaitu:

1. Kepercayaan Terhadap Pimpinan $\left(X_{3}\right)$;

2. Mutasi $\left(X_{12}\right)$;

3. Budaya Organisasi $\left(X_{3}\right)$;

b. Variabel Dependent (Endogeneus) Interverning terdiri atas 1 (satu), yaitu Motivasi Kerja (Z).

c. Variabel Dependent (Endogeneus) terdiri atas 1 (satu), yaitu Kinerja Pegawai (Y).

Data yang terkumpul dianalisis dengan analisis Structural Equation Modeling (SEM) yang merupakan penggabungan dari analisis jalur (path analysis) dan model pengukuran (measurement model) yaitu analisis faktor (Confirmatory Faktor Analysis). Secara umum, ada dua alat analisis utama dalam penelitian ini, yaitu: (1) alat uji asumsi SEM, dan (2) alat uji kecocokan model.

\section{Hasil dan Pembahasan}

Setelah diketahui bahwa model dalam analisis ini telah fit maka analisis selanjutnya adalah mengetahui tingkat hubungan dan signifikansi atau kebermaknaan hubungan antar variabel yang ada dalam penelitian ini. Hasil pengujian dengan program SEM memberikan hasil model persamaan struktural yang menunjukkan adanya hubungan antar variabel mutasi kerja dengan motivasi kerja, budaya organisasi dengan motivasi kerja, kepercayaan terhadap pimpinan dengan kepuasan, mutasi kerja dengan kinerja, budaya organisasi dengan kinerja, kepercayaan terhadap pimpinan dengan motivasi kerja, dan motivasi kerja dengan kinerja.

Setelah diketahui gambaran hubungan antara variabel-variabel penelitian ini maka selanjutnya akan dipaparkan hasil pengujian hipotesis. Dalam hal ini akan disajikan nilai koefisien jalur antar variabel berikut signifikansi hasil uji hipotesis pada Tabel 1 di bawah ini. 
Tabel 1: Nilai Koefisien Jalur dan Pengujian Hipotesis

\begin{tabular}{|c|c|c|c|c|c|c|}
\hline \multicolumn{3}{|c|}{ Variabel } & \multirow{2}{*}{$\begin{array}{c}\begin{array}{c}\text { Koefisien } \\
\text { Jalur }\end{array} \\
0,074\end{array}$} & \multirow{2}{*}{$\begin{array}{c}\text { C.R } \\
2,539\end{array}$} & \multicolumn{2}{|c|}{ Probabilitas Keterangan } \\
\hline $\begin{array}{l}\text { Kepercayaan } \\
\text { Terhadap } \\
\text { Pimpinan }(X 1)\end{array}$ & $\rightarrow$ & $\begin{array}{l}\text { Motivasi } \\
\quad(Z)\end{array}$ & & & 0,010 & Signifikan \\
\hline Mutasi (X2) & $\rightarrow$ & $\begin{array}{l}\text { Motivasi } \\
(Z)\end{array}$ & 0,170 & 2,604 & 0,009 & Signifikan \\
\hline $\begin{array}{c}\text { Budaya } \\
\text { Organisasi } \\
(\mathrm{X} 3)\end{array}$ & $\rightarrow$ & $\begin{array}{l}\text { Motivasi } \\
\quad(\mathrm{Z})\end{array}$ & 0,193 & 2,444 & 0,014 & Signifikan \\
\hline Motivasi (Z) & $\rightarrow$ & Kinerja $(\mathrm{Y})$ & 0,025 & 2,785 & 0,032 & Signifikan \\
\hline $\begin{array}{l}\text { Kepercayaan } \\
\text { Terhadap } \\
\text { Pimpinan (X1) }\end{array}$ & $\rightarrow$ & Kinerja $(\mathrm{Y})$ & $-0,007$ &,- 181 & 0,857 & $\begin{array}{c}\text { Tidak } \\
\text { Signifikan }\end{array}$ \\
\hline Mutasi (X2) & $\rightarrow$ & Kinerja $(\mathrm{Y})$ & 1,003 & 10,399 & 0,000 & Signifikan \\
\hline $\begin{array}{l}\text { Budaya_Organ } \\
\text { isasi (X3) }\end{array}$ & $\rightarrow$ & Kinerja $(Y)$ & $-0,028$ &,- 765 & 0,444 & $\begin{array}{c}\text { Tidak } \\
\text { Signifikan }\end{array}$ \\
\hline
\end{tabular}

Sumber: Hasil Analisis Data

Faktor motivasi kerja dan kinerja pegawai merupakan sesuatu yang penting di dalam suatu instansi karena banyak penelitian menunjukkan bahwa motivasi kerja berhubungan dengan peningkatan kinerja pegawai. Berdasarkan analisis data sebelumnya dapat diketahui bahwa beberapa faktor sumber daya manusia antara lain mutasi kerja, budaya organisasi dan kepercayaan terhadap pimpinan berpengaruh terhadap motivasi kerja dan kinerja. Hasil tersebut didukung pula dengan hasil analisis deskriptif jawaban responden terhadap variabel kepercayaan terhadap pimpinan, mutasi kerja, budaya organisasi, motivasi kerja dan kinerja. Hasil penelitian tersebut dijelaskan selengkapnya sebagai berikut.

\section{Pengaruh Kepercayaan Terhadap Pimpinan pada Motivasi Kerja Pegawai}

Kepercayaan terhadap pimpinan ditujukan agar pegawai mempunyai kemampuan yang lebih tinggi dari kemampuan yang dimiliki sebelumnya sehingga dapat mengetahui fungsi, peranan serta tanggung jawabnya di dalam lingkungan kerja. Berdasarkan hasil analisis SEM pengaruh yang ditimbulkan variabel kepercayaan terhadap pimpinan tidak berpengaruh signifikan terhadap motivasi kerja pegawai, diketahui bahwa kepercayaan terhadap pimpinan tidak memberikan motivasi bagi pegawai. Hasil penelitian ini tidak sesuai dengan penelitian Wibowo (2006) yang menemukan bahwa kepercayaan terhadap pimpinan berpengaruh signifikan terhadap motivasi kerja. Motivasi kerja seorang pegawai tidak dapat meningkat adanya kepercayaan terhadap pimpinan yang diterapkan oleh pimpinan. 


\section{$\underline{\text { Pengaruh Faktor Mutasi Kerja Terhadap Motivasi Kerja Karyawan }}$}

Berdasarkan hasil analisis SEM mutasi kerja berpengaruh signifikan terhadap motivasi kerja. Pada penelitian ini terlihat pengaruh secara langsung variabel mutasi kerja terhadap motivasi kerja pegawai Badan Pendapatan Daerah Kabupaten Jember terbukti signifikan. Hal itu berarti bahwa hipotesis kedua yang menyatakan mutasi kerja berpengaruh signifikan terhadap motivasi kerja, terbukti. Berdasarkan hasil penilaian responden menunjukkan bahwa mutasi kerja yang dipersepsikan secara baik oleh pegawai dan mutasi kerja berpengaruh signifikan terhadap motivasi kerja pegawai. Budaya organisasi yang kuat mendukung tujuan-tujuan instansi, sebaliknya akan menghambat dengan tujuan-tujuan instansi. Budaya yang kuat dan positif sangat berpengaruh terhadap motivasi kerja.

\section{Pengaruh Faktor Budaya Organisasi Terhadap Motivasi Kerja Karyawan}

Budaya organisasi dan budaya perusahan saling terkait karena kedua-duanya ada kesamaan, meskipun dalam budaya organisasi terdapat hal-hal khusus seperti gaya manajemen, sistem manajemen dan sebagainya, namun semuanya tetap dalam rangkaian budaya perusahaan. Berdasarkan nilai analisis SEM, budaya organisasi berpengaruh signifikan terhadap motivasi kerja. Pada penelitian ini pengaruh secara langsung budaya organisasi terhadap motivasi kerja pegawai Badan Pendapatan Daerah Kabupaten Jember adalah signifikan. Hal itu berarti bahwa hipotesis ketiga yang menyatakan budaya organisasi berpengaruh signifikan terhadap motivasi kerja, terbukti. Berdasarkan hasil penilaian responden menunjukkan bahwa budaya organisasi yang dipersepsikan secara baik oleh pegawai. Hal ini disebabkan karena budaya organisasi di Badan Pendapatan Daerah Kabupaten Jember dilakukan secara baik maka akan menimbulkan kinerja yang baik pula bagi pegawai. Budaya yang kuat dan positif sangat berpengaruh terhadap motivasi kerja.

Hasil studi ini konsisten dengan penelitian Maryani et.al. (2011) bahwa budaya organisasi secara signifikan mempengaruhi motivasi kerja pegawai. Jenis kemampuan, keterampilan dan pemenuhan tugas akan dapat mempengaruhi motivasi kerja secara positif.

\section{Pengaruh Kepercayaan Terhadap Pimpinan pada Kinerja Pegawai}

Hasil analisis menunjukkan bahwa kepercayaan terhadap pimpinan berpengaruh positif dan tidak signifikan terhadap kinerja pegawai di Badan Pendapatan Daerah Kabupaten Jember. Hal itu menunjukkan bahwa hipotesis 
keempat yang menyatakan semakin baik atau tepat kepercayaan terhadap pimpinan maka akan semakin meningkat kinerja pegawai di Badan Pendapatan Daerah Kabupaten Jember, tidak terbukti atau tidak dapat diterima. Artinya penerapan kepercayaan terhadap pimpinan pada Badan Pendapatan Daerah Kabupaten Jember tidak mempengaruhi kinerja pegawai. Hasil penelitian sesuai dengan Wibowo (2006) yang menemukan bahwa kepercayaan terhadap pimpinan tidak berpengaruh signifikan terhadap kinerja.

\section{Pengaruh Faktor Mutasi Kerja Terhadap Kinerja Pegawai}

Berdasarkan hasil analisis SEM, mutasi kerja berpengaruh signifikan terhadap kinerja. Pada penelitian ini terlihat pengaruh secara langsung mutasi kerja terhadap kinerja pegawai Badan Pendapatan Daerah Kabupaten Jember adalah signifikan. Hal itu berarti bahwa hipotesis kelima yang menyatakan mutasi kerja berpengaruh signifikan terhadap kinerja, terbukti. Berdasarkan hasil penilaian responden diketahui bahwa mutasi kerja yang dipersepsikan secara baik oleh pegawai berpengaruh signifikan terhadap kinerja pegawai. Hal ini disebabkan mutasi kerja dilakukan dengan cukup baik yang kemudian meningkatkan kinerja yang baik pula bagi pegawai.

Hasil studi ini konsisten dengan penelitian Saravani dan Abbasi (2013) bahwa mutasi kerja secara signifikan mempengaruhi kinerja pegawai. Mutasi kerja akan dapat mempengaruhi kinerja secara positif. Tetapi dalam penelitian ini mutasi kerja masih dipengaruhi di birokrasi instansi belum sepenuhnya sama dengan kinerja pegawai yang tergantung pada kinerja pegawai secara individu.

\section{Pengaruh Faktor Budaya Organisasi Terhadap Kinerja Pegawai}

Hasil analisis menunjukkan bahwa budaya organisasi tidak berpengaruh signifikan terhadap kinerja pegawai pegawai di Badan Pendapatan Daerah Kabupaten Jember. Berarti hipotesis keenam yang menyatakan bahwa semakin kuat budaya organisasi maka semakin tinggi kinerja pegawai ditolak. Hasil ini didukung dengan penilaian pegawai tentang budaya organisasi yang pada umumnya memiliki penilaian cukup setuju dan setuju. Hal itu dapat diartikan bahwa pegawai memiliki persepsi yang cukup baik terhadap budaya organisasi yang diterapkan di Badan Pendapatan Daerah Kabupaten Jember.

Hasil penelitian ini menunjukkan bahwa budaya organisasi sebagai bagian dari suatu sistem mempengaruhi perilaku internal pegawai dalam meningkatkan kinerja pegawai pegawai Badan Pendapatan Daerah Kabupaten Jember. Jika kumpulan nilai-nilai dari individu-individu ini berpadu menjadi keyakinan bersama 
(common values) dan dihayati dalam kehidupan sehari-hari organisasi, maka terbentuklah budaya organisasi. Lebih penting lagi, budaya yang terbentuk melalui proses tersebut dapat dikatakan mewujud secara baik apabila teraktualisasi dalam perilaku anggotanya sehari-hari (behavior) dan akhirnya menjadi pola kebiasaan (habit).

Hasil studi ini tidak konsisten dengan penelitian Chaudhry (2012) dan Koesmono (2013) bahwa budaya organisasi mempengaruhi kinerja pegawai. Jenis kemampuan, keterampilan dan pemenuhan tugas akan dapat mempengaruhi kinerja secara positif.

Implementasi pengaruh budaya organisasi terhadap kinerja di Badan Pendapatan Daerah di Kabupaten Jember diwujudkan dengan capaian indikator kinerja utama pada perspektif customer. Adanya penerapan budaya yang kuat oleh pegawai Badan Pendapatan Daerah akan meningkatkan kepuasan pengguna jasa dari Badan Pendapatan Daerah Kabupaten Jember.

\section{Pengaruh Motivasi Kerja Terhadap Kinerja Pegawai}

Motivasi kerja terbukti dalam pengujian berpengaruh signifikan terhadap motivasi kerja. Berdasarkan nilai perhitungan SEM yang ditimbulkan variabel motivasi terhadap kinerja pegawai secara langsung. Pada penelitian ini terlihat ada pengaruh secara langsung yang diberikan faktor motivasi terhadap kinerja pegawai Badan Pendapatan daerah Kabupaten Jember. Motivasi yang dipersepsikan secara langsung mempunyai efek positif terhadap kepuasan secara keseluruhan. Hal itu menunjukkan bahwa motivasi kerja dapat mempengaruhi kinerja pegawai. Pada penelitian ini motivasi yang baik mendukung aktivitas kerja pegawai sehingga pegawai akan merasakan kinerja, faktor motivasi berpengaruh positif terhadap kinerja.

Implementasi dari motivasi kerja yang telah dilakukan oleh Badan Pendapatan daerah Kabupaten Jember dalam meningkatkan kinerja antara lain:

a. Memberikan Training kepada seluruh pegawai sesuai dengan golongannya.

b. Mengajukan assessment bagi karyawan yang berprestasi untuk ke jenjang yang lebih tinggi.

c. Assessment bagi karyawan yang berprestasi untuk ke jenjang yang lebih tinggi. 
Adanya motivasi kerja tersebut akan meningkatkan kinerja. Hasil penelitian ini konsisten dengan Muogbo (2013) menemukan bahwa Motivasi berpengaruh terhadap kinerja.

\section{Kesimpulan}

Berdasarkan hasil penelitian dapat disimpulkan, yaitu : (a) Kepercayaan terhadap pimpinan berpengaruh signifikan terhadap motivasi kerja. Gaya kepemimpinan tranformasional yang dilakukan tidak dapat meningkatkan motivasi kerja pegawai; (b) Mutasi kerja berpengaruh terhadap signifikan motivasi kerja. Mutasi yang dilakukan dengan baik maka motivasi kerja pegawai semakin meningkat; (c) Budaya organisasi berpengaruh signifikan terhadap motivasi kerja. Budaya organisasi yang baik dapat meningkatkan motivasi kerja pegawai; (d) Kepercayaan terhadap pimpinan tidak berpengaruh signifikan terhadap kinerja. Kepercayaan terhadap pimpinan yang diterapkan tidak dapat meningkatkan kinerja pegawai; (e) Mutasi kerja berpengaruh signifikan terhadap kinerja. Apabila mutasi kerja dilakukan sesuai prosedur maka kinerja juga akan meningkat; (f) Budaya organisasi tidak berpengaruh signifikan terhadap kinerja. Budaya organisasi tidak dapat meningkatkan kinerja; (g) Motivasi kerja berpengaruh signifikan terhadap kinerja. Jika motivasi kerja semakin tinggi maka kinerja juga akan meningkat.

\section{Saran}

Saran yang dapat diajukan berdasarkan hasil penelitian, yaitu: (a) Kepercayaan terhadap kepemimpinan yang diterapkan di Badan Pendapatan Daerah Kabupaten Jember hendaknya lebih diperkuat lagi, yaitu kepercayaan terhadap kepemimpinan yang mampu menyesuaikan dengan situasi dan kondisi (situasional) pimpinan, bawahan dan lingkungan; (b) Para pimpinan di lingkungan Badan Pendapatan Daerah diharapkan terus meningkatkan motivasi dengan jalan tidak mengabaikan hak dan kepentingan pegawai yang bersangkutan. Seperti, memberikan kesempatan promosi, perbaikan sistem pengawasan pegawai, meningkatkan kemampuan sehingga dorongan pada pegawai dapat memacu kinerja; (c) Penelitian selajutnya dapat mengukur variabel dengan persepsi yang lain, terutama persepsi atasan (supervisor atau manager), dengan tujuan untuk mengukur dan mengidentifikasikan kecenderungan kinerja pegawai untuk perbaikan manajemen selanjutnya; (d) Penelitian selanjutnya dapat menambah variabel- 
variabel lain, sebagai variabel kepuasan, kompensasi dan dilakukan dengan perbandingan di Kementrian Dalam Negeri lainnya.

\section{Daftar Referensi}

Abbasi, B and Saravani, S.R. 2013. Investigating The Influence of Job Rotation on Performance. By Considering Skill Variation and Job Satisfaction of Bank Employee's. Technical Gazette 20 No.3 : 473-478.

Adjei, D. 2012. The Impact of Job Relation on Employee's Performance A Case Study

Chaudhry, Abdul Qayyum, Husnain Javed dan Munawar Sabir. 2012. The Impact Of Transformational And Transactional Leadership Styles On The Motivation Of Employees In Pakistan. Pakistan Economic and Social Review . Volume 50, No. 2 (Winter 2012), pp. 223-231

Mudrajad Kuncoro. 2004. Metode Kuantitatif: Teori dan Aplikasi untuk Bisnis dan Ekonomi. UPP AMP YKPN. Yogyakarta

Maryani. Armanu Thoyib. Margono Setiawan. dan Ubud Salim. 2011. Pengaruh Budaya Organisasi dan Gaya Kepemimpinan serta Pengembangan Karyawan terhadap Kepuasan Kerja dan Kinerja Karyawan pada Perusahaan Ritel di Sulawesi Selatan. JAM. Volume 9 Nomor 3. Mei 2011.

Muogbo U.S, 2013, The Impact of Employee Motivation On Organisational Performance (A Study Of Some Selected Firms In Anambra State Nigeria), The International Journal Of Engineering And Science (IJES), Volume2, Issue7, Pages 70 - 80

Koesmono, H. Teman. 2013. Pengaruh Budaya Organisasi Terhadap Motivasi Dan Kepuasan Kerja Serta Kinerja Karyawan Pada Sub Sektor Industri Pengolahan Kayu Skala Menengah Di Jawa Timur. Jurnal Manajemen \& Kewirausahaan, Vol. 7, NO. 2, September 2005. h. 162-179.

Wibowo, 2006. Manajemen Kinerja, Edisi Kedua, PT. Raja Grafindo Persada,. Jakarta. 